\title{
Abiotrophia defectiva endocarditis presenting with hemiplegia
}

\author{
Yasemin Akkoyunlu ${ }^{1,{ }^{*}}$, Meryem Iraz ${ }^{2}$, Gulsen Kocaman ${ }^{3}$, Bahadir Ceylan ${ }^{1}$, Cemalettin \\ Aydin ${ }^{4}$, Turan Aslan ${ }^{1}$ \\ ${ }^{1}$ Department of Infectious Diseases and Clinical Microbiology, School of Medicine, Bezmialem Vakif University, Istanbul, Turkey \\ 2 Department of Clinical Microbiology, School of Medicine, Bezmialem Vakif University, Istanbul, Turkey \\ 3 Department of Neurology, School of Medicine, Bezmialem Vakif University, Istanbul, Turkey \\ 4 Department of Neurology, School of Medicine, Bezmialem Vakif University, Istanbul, Turkey
Department of Cardiovasculer Surgery, School of Medicine, Bezmialem Vakif University, Istanbul, Turkey \\ ${ }^{*}$ Corresponding author: Yasemin Akkoyunlu, Department of Infectious Diseases and Clinical Microbiology, School of Medicine, Bezmialem Vakif University, Vatan Cad. Fatih, 34093, \\ Istanbul, Turkey. Tel:+90-5301436555, Fax:+90-2125332326, E-mail:yaseminakkoyunlu@gmail.com.
}

Received: November 01, 2012; Revised: January 30, 2013; Accepted: March 03, 2013

\begin{abstract}
Abiotrophia defectiva was previously known as a member of the nutritionally variant streptococcus (NVS). This microorganism is a member of the normal flora of mouth, urogenital and intestinal tracts. It causes various infections such as bacteriemia, brain abscess, septic arthritis and rarely infective endocarditis. Only $<1 \%$ of all cases of endocarditis are caused by A. defectiva.

A 23 year old previously healthy female was admitted to emergency department for left hemiplegia. On physical examination, petechial rashes were detected on her palmar and plantar regions. Magnetic resonance image of brain revealed acute enfarctus in the striatocapsuler area, and total occlusion was detected in right median common arterial segment M1 with magnetic resonance imaging angiography. Urgent thrombectomy was performed. Echocardiography demonstrated a mobile vegetation on mitral valve leaflet.

Infective endocarditis was diagnosed and ceftriaxone at $2 \mathrm{gr} /$ day and vancomycin at $2 \mathrm{gr} /$ day doses were started. A. defectiva was isolated in blood cultures. Antibiotics were changed to ampicillin/sulbactam at $8 \mathrm{gr} /$ day and vancomycin at $2 \mathrm{gr} /$ day doses. Infective endocarditis caused by A. defectiva and other nutritionally variant streptococci are reported to have a higher mortality, morbidity and complication rates. In the current communication we report this rather rare case of infective endocarditis.
\end{abstract}

Keywords: Abiotrophia defectiva, Endocarditis, Hemiplegia, Streptococci

\section{Introduction}

Abiotrophia defectiva was previously known as a member of the nutritionally variant streptococcus (NVS) (1). The NVS was first described in 1961 by Hirsch and Frenkel as new types of viridans streptococci according to phenotypic characteristics (2). This microorganism is a member of the normal flora of mouth, urogenital and intestinal tracts. It causes various infections such as bacteriemia, brain abscess, septic arthritis and rarely infective endocarditis $(3,4)$. Only $<1 \%$ of all cases of endocarditis are caused by A. defectiva (1). Abiotrophia species causing endocarditis represent 5-6\% of all streptococcal endocarditis cases (5).

\section{Case Presentation}

A-23-year-old previously healthy female admitted to emergency service of a university hospital with complaints of left hemiplegia for a few hours. The patient had a history of left leg pain for 3 months. Also, there was his- tory of a tooth extraction followed by intermittant fever and maculopapuler rash on her legs at the beginning of the leg pain. These symptoms were resolved without any treatment. A few weeks later, symptoms were resurfaced and the patient was given methotrexate $10 \mathrm{mg} / \mathrm{week}+$ prednisolone $10 \mathrm{mg} /$ day with the diagnosis of rheumatoid arthritis ten days before.

On admission, her temperature was $36.8^{\circ} \mathrm{C}$, and the pulse was 98 beats per minute, with the blood pressure of $162 / 104 \mathrm{mmHg}$. On physical examination, petechial rashes were detected on her palmar and plantar regions. Her blood values were; white blood cell count, $7.860 / \mathrm{mm}^{3}$; hgb, 9, 8 g/dL; platelet count, $266.000 / \mathrm{mm}^{3}$;C-reactive protein (CRP), 2,12 mg/dL; erytrocyte sedimentation rate (ESR), $72 \mathrm{~mm} / \mathrm{h}$. Previous laboratory result for rheumatoid factor were $25,6 \mathrm{IU} / \mathrm{mL}$ and C-reactive protein was 9,13 $\mathrm{mg} / \mathrm{dL}$. The magnetic resonance images of the brain revealed acute enfarctus in the striatocapsuler area and a total occlusion was detected in the right median common arterial segment M1 with MR angiography (Figure 1).

Implication for health policy/practice/ research/medical education

A. defectiva must be remembered by clinicians and microbiologists in cases with bacteremia and endocarditis. Favorable outcome can be reached with early diagnosis, efficient and prolonged antibiotic treatment and surgical management by multidisciplinary approach in this rare but risky disease.

Copyright (C) 2013, Ahvaz Jundishapur University of Medical Sciences; Licensee Kowsar Ltd. This is an Open Access article distributed under the terms of the Creative Commons Attribution License (http://creativecommons.org/licenses/by/3.0), which permits unrestricted use, distribution, and reproduction in any medium, provided the original work is properly cited. 
Urgent thrombectomy was performed. Echocardiography demonstrated a mobile vegetation on the mitral valve leaflet. Infective endocarditis was diagnosed using modified Duke's criteria (6). Ceftriaxone $2 \mathrm{gr} /$ day and vancomycin 2 gr/day were started to the patient. On the 3rd day after the treatment, her femoral pulse disappeared and femoral thrombus was detected with doppler ultrasound. Femoral thrombectomy was done concurrently with mitral valve replacement.

Three sets of blood cultures were positive for Gram-positive coccobacillus. Gram-positive coccobacillus grown in chocolate blood agar was identified as A. defectiva. Antibiotic was changed to -ampicillin/sulbactam 8 gr/day + vancomycin $2 \mathrm{gr} /$ day. Blood cultures collected at the end of the first week of antimicrobial treatment were sterile. Antibiotics were continued for 6 weeks where ampicillin/ sulbactam mono therapy ensued after third week. At the end of therapy, laboratory findings were as follows: white blood cell count: $9.4000 / \mathrm{mm}^{3}$, hgb:11, $1 \mathrm{~g} / \mathrm{dL}$, platelet count: $413.000 / \mathrm{mm}^{3}$, CRP:0,9 $\mathrm{mg} / \mathrm{dL}, \mathrm{ESR}: 30 \mathrm{~mm} / \mathrm{h}$. By the end of six weeks, the patient recovered from endocarditis and discharged. However, the hemiplegia continued and physiotherapy was prescribed.

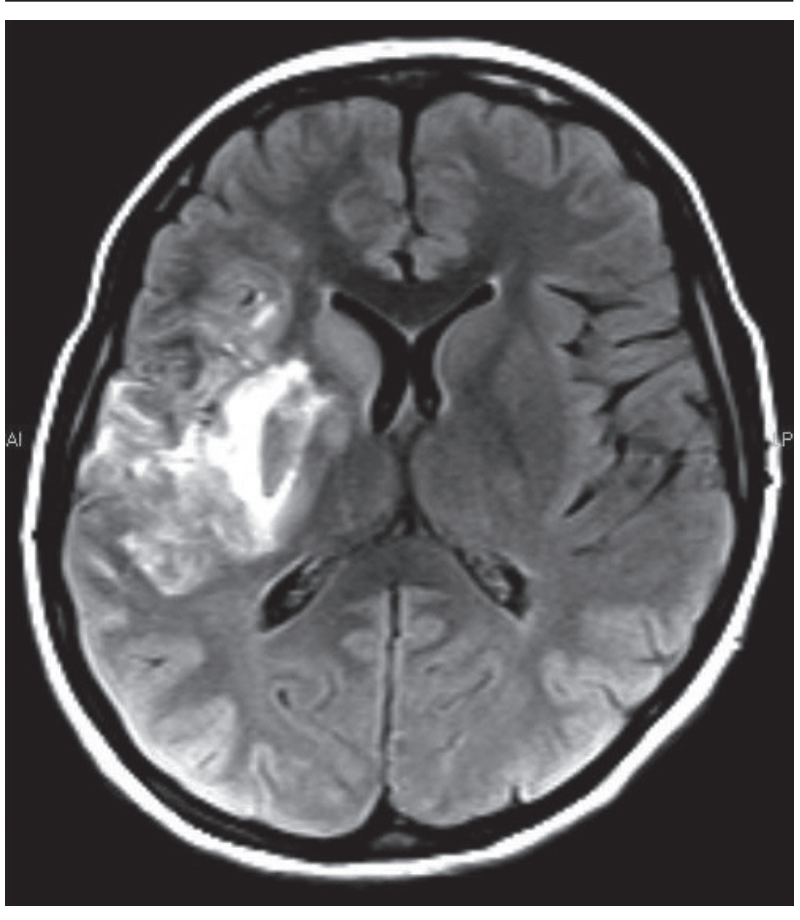

Figure 1. Axial T1W Mr Image Showed Subacute Phase Hemorrhagic Infarction Within the Right Middle Cerebral Artery (MCA) Territory

\section{Discussion}

Nutritionally variant streptococci were first described in 1961(2). Later, NVS was classified into Streptococcus adjacens and S. defectives in 1989. In 1995, A. defectiva was reclassified independently as Abiotrophia genus based on
RNA analysis (1). This fastidious microorganism has been reported to be a common cause of culture-negative bacterial endocarditis (7). Prior heart disease such as congenital valvular heart disease or heart valve prosthesis, dental manipulations were considered as risk factors for A. defectiva endocarditis as another streptococcal endocarditis. The antibiotic regimen of $A$. defectiva endocarditis should include penicillin or ampicillin plus an aminoglycoside or vancomycine in case of antimicrobial resistance for 4 to 6 weeks $(1,3,5)$.

Infective endocarditis caused by A. defectiva and other NVS has a higher mortality, morbidity and complication rates than those caused by other viridans streptococci. The identification and cultivation of A. defectiva is very difficult because it is a delicate microorganism which grows rather gently and scarcely than other streptococci $(1,3)$. In case series of endocarditis caused by NVS; relapse occurred in $17 \%$ of cases, bacteriological failure in $41 \%$ of cases (8). Infective endocarditis due to A. defectiva progresses slowly, despite its sensitivity to antimicrobials nearly half of the cases need surgical management (4). This slowly growing microorganism can unusually result and present with such morbidity like cerebrovasculary disease and hemiplegia as our patient. Morbidity and mortality rates are higher than those associated with other forms of viridans streptococcal and enterococcal endocarditis. Although the bactericidal effect was demonstrated in vitro, antibiotic therapy failed in $41 \%$ of patients. About $27 \%$ of patients required heart valve replacement surgery and mortality rate was approximately $20 \%$ (7).

Heart failure is the most serious complication of endocarditis and often requires valve replacement (3). Persistent sepsis, persistent vegetations, severe congestive heart failure and recurrent embolism are major indications for surgical management. A. defectiva caused endocarditis is difficult to cure (5). Prolonged antibiotic treatment is crucial whereas most cases need valve replacement. Previously, mortality and morbidity were reported even in cases with early diagnosis or appropriate antibiotic therapy (7). Our case underwent mitral valve replacement due to extensive valvular damage and recurrent septic embolism. In our patient, because of subacute presentation of the clinical features, the diagnosis could be made after embolization. During the 3 months between initial symptoms and diagnosis, the patient was not evaluated for infectious etiologies until the detection of the cardiac vegetation.

In conclusion, A. defectiva should be considered by clinicians and microbiologists in cases with bacteremia and endocarditis. Favorable outcome can be reached with early diagnosis followed by efficient and prolonged antibiotic treatment and surgical management by the multidisciplinary approach in this rare but risky disease.

\section{Acknowledgements}

None declared. 


\section{Authors' Contribution}

None declared.

\section{Financial Disclosure}

None declared.

\section{Funding/Support}

None declared.

\section{References}

1. Yang YS, Shang ST, Lin JC, Chiu CH, Chang FY. A ruptured cerebral mycotic aneurysm caused by Abiotrophia defectiva endocarditis. Am J Med Sci. 2010;339(2):190-1.

2. Frenkel A, Hirsch W. Spontaneous development of L forms of streptococci requiring secretions of other bacteria or sulphydryl compounds for normal growth. Nature. 1961;191:728-30.

3. Al-Jasser AM, Enani MA, Al-Fagih MR. Endocarditis caused by Abiotrophia defectiva. Libyan J Med. 2007;2(1):43-5.
4. Yemisen M, Koksal F, Mete B, Yarimcam F, Okcun B, Kucukoglu S, et al. Abiotrophia defectiva: a rare cause of infective endocarditis. Scand J Infect Dis. 2006;38(10):939-41.

5. Takayama R, Motoyasu M, Seko T, Kuroda K, Yamanaka T, Obe T, et al. A case of isolated tricuspid valve infective endocarditis caused by Abiotrophia defectiva. Int J Cardiol. 2007;118(1):e3-5.

6. Baddour LM, Wilson WR, Bayer AS, Fowler VG, Jr, Bolger AF, Levison ME, et al. Infective endocarditis: diagnosis, antimicrobial therapy, and management of complications: a statement for healthcare professionals from the Committee on Rheumatic Fever, Endocarditis, and Kawasaki Disease, Council on Cardiovascular Disease in the Young, and the Councils on Clinical Cardiology, Stroke, and Cardiovascular Surgery and Anesthesia, American Heart Association: endorsed by the Infectious Diseases Society of America. Circulation. 2005;111(23):e394-434.

7. Giuliano S, Caccese R, Carfagna P, Vena A, Falcone M, Venditti M. Endocarditis caused by nutritionally variant streptococci: a case report and literature review. Infez Med. 2012;20(2):67-74.

8. Stein DS, Nelson KE. Endocarditis due to nutritionally deficient streptococci: therapeutic dilemma. Rev Infect Dis. 1987;9(5):90816.

9. Al-Jasser AM, Enani MA, Al-Fagih MR. Endocarditis caused by Abiotrophia defectiva. Libyan J Med. 2007;2(1):43-5. 